\title{
BALNEÁRIO PRAIA DAS AREIAS BRANCAS DE ROSÁRIO DO SUL/RS: UM OLHAR DA EDUCAÇÃO AMBIENTAL'
}

\author{
Marlei Balzan Vendruscolo², Dionísio Link \\ ${ }^{1}$ Parte da Monografia de Especialização "Balneário praia das areias brancas de Rosário do Sul: um olhar da educação \\ ambiental no Município de Rosário do Sul/RS", desenvolvida no Programa de Pós-graduação à distância em Educação \\ Ambiental da Universidade Federal de Santa Maria (UFSM). \\ ${ }^{2}$ Autora. Professora, Acadêmica do Curso de Especialização à distância em Educação Ambiental da UFSM. \\ marleibalzanvendruscolo@hotmail.com \\ ${ }^{3}$ Orientador. Professor, Doutor \\ dionisiolink@yahoo.com.br
}

\section{RESUMO}

Sendo a água parte vital no desenvolvimento e na manutenção de todas as formas de vida na biosfera terrestre, percebe-se a importância desse recurso natural, visto que a vida muito provavelmente se originou nesse meio...Este estudo tem como principal objetivo a leitura de uma análise da qualidade da água do Balneário Praia das Areias Brancas, em Rosário do Sul visando as condições de banho e recreação sem causar prejuízos a população. A balneabilidade do local foi avaliada através dos resultados de análise das águas, coletadas pela FEPAM no período 2007/2008. Verificou-se que os níveis de contaminação encontrados foram pequenos, não afetando à balneabilidade do local. Através de um questionário aplicado a moradores do entorno, constatou-se que a maioria tem conhecimento da atual situação e que procedimentos devem ser tomados ou mantidos para manter em boas condições o balneário.

PALAVRA-CHAVE: água - balneabilidade - Coliformes fecais.

\section{ABSTRACT}

Because water is a vital part in the development and maintenance of all life forms in the terrestrial biosphere, realizes the importance of this resource, given that life probably originated in this way .. This study's main objective reading an analysis of the water quality of the Spa White Sands Beach, in Rosario do Sul order conditions and recreation facilities without causing harm to the population. The bathing site was evaluated by results of analysis of water collected by FEPAM the period 2007/2008. It was found that levels of contamination found were small, not affecting the 
Monografias Ambientais

(e-ISSN: 2236-1308)

REMOANFSM

bathing site. Through a questionnaire administered to the surrounding residents, it was found that the majority is aware of the current situation and what procedures should be taken or maintained in good condition to keep the spa.

KEY WORDS: Bathing - Fecal coliforms

Este artigo faz um recorte da monografia do curso de Especialização à distância em Educação Ambiental intitulada "Balneário Praia das Areias Brancas de Rosário do Sul $\backslash$ RS: Um Olhar da Educação Ambiental”. O Balneário Praia das Areias Brancas, é bastante freqüentado pela população de Rosário do Sul e também por vários veranistas que passam por Rosário do Sul.

A população de Rosário do Sul enfrenta sérios riscos que ocorrem com à falta de saneamento básico, hábitos culturais e falta de educação sanitária e falta de informações. A falta de sistemas de esgoto ou de condições sanitárias é uma constante, não restrito às zonas ribeiras, porém lixos domésticos às margens do rio, animais na praia, tornam a água e a areia impróprias para banho, e para outros fins para a população que ultiliza o Balneário Praia das Areis Brancas.

O presente trabalho tem como tema: "Qualidade da água do Balneário da Praia das Areias Brancas", e delimita-se á "Importância do controle da qualidade da água utilizada pela população no entorno do balneário da Praia das Areias Brancas em Rosário do Sul \RS", e visa responder se na maior parte o Balneário tem condições apropriadas para a população e os veranistas freqüentarem para banho e lazer ¿ O objetivo geral desta monografia de especialização e fazer uma análise da qualidade da água do Balneário Praia das Areias Brancas \RS visando saber se a mesma está em condições para banho e recreação sem causar prejuízos à saúde da população.

Adotou-se como metodologia uma pesquisa quantitativa. A pesquisa envolve levantamento bibliográfico através do site da Fepam e os dados foram coletados através de entrevistas com pessoas que moram em torno do Balneário Praia das Areias Brancas, com moradores que tem experiências com o problema pesquisado.

O trabalho tem como objetivos, em saber se o balneário Praia das Areias Brancas está em condições apropriadas para recreação dos veranistas para lazer e recreação. 
Por fim, propor alternativas para a conscientização e preservar o Balneário, não jogando lixo, não levando animais para banho nas águas. Deve-se-ia elaborar um projeto, por parte da administração pública em conjunto com a população para evitar que o esgoto que é lançado direto no rio receba um tratamento prévio ou pelo menos, não seja ali despejado.

Foi também aplicado um questionário onde os moradores colocaram seus pontos de vista, conhecimentos e habilidades nas respostas dadas ao questionário e seus questionamentos sob o ponto de vista ambiental, foram entrevistados 100 moradores na zona ribeirinha do Balneário Praia das Areias Brancas. A maior parte da população pesquisada freqüenta habitualmente o balneário e aproveita à areia e a água para seu lazer e descanso. A verdade é que se desenvolveu a idéia de que a Praia das Areias Brancas estaria imprópria para banho recreação. Através desta pesquisa esse fato não é verdadeiro. Portanto, entende-se que as boas condições da água do Balneário devem ser divulgadas para a população, bem como para os municípios vizinhos e turistas que visitam Rosário do Sul, especialmente no período de novembro a março enfocando que tanto as águas quanto seu entorno possuem condições adequadas para balneabilidade.

Durante a realização deste trabalho tivemos conhecimentos que com as más condições de sistemas sanitários do Balneário, tornam a água e a areia impróprias para banho, e para outros fins da população, devido principalmente a alta concentração de Coliformes fecais que se acumulam devido as más condições de uso. A detecção de agentes patogênicos em uma amostra d' água é extremamente difícil, em razão das baixas concentrações. Este obstáculo é superado pelos estudos chamados organismos indicadores de contaminação fecal. Tais organismos não são patogênicos, mas dão indicação quando a água apresenta contaminação por fezes humanas ou de animais e sua potencialidade para a transmissão de doenças. Os organismos mais usados são as bactérias do grupo coliforme.

Os coliformes termotolerantes vivem normalmente no organismo humano e nos demais animais de sangue quente, existindo em grande quantidade nas fezes. Entre as bactérias do grupo coliforme, a mais usada como indicadora da poluição fecal é a Escherichi coli.

Os coliformes são definidos como bastonetes gram-negativos, que fermentam lactose com produção de gás em 48 horas de incubação em caldo lactosado a $35^{\circ} \mathrm{C}$. O coliforme termotolerante predominante é a $E$. coli, que constitui uma grande proporção da população bacteriana intestinal humana. 
REMOANFSM

A poluição por coliformes da água pode causar algumas doenças nas pessoas como: Amebíase ou Disenteria amebiana, Ascaridíase, ou Lombriga, Anciclostomose, Cólera, Esquitossomose, Hepatite A.

Todo o trabalho foi realizado no município de Rosário do Sul, o qual é uma cidade brasileira localizada no estado do Rio Grande do Sul, na região centro-oeste. Faz fronteira com as cidades de São Gabriel, Cacequi, Alegrete, Santana do Livramento, Quarai e Dom Pedrito. Está distante 386 Km da capital do estado de Porto Alegre. A população estimada de residentes do município aproximadamente 40.509 habitantes. Atualmente a legislação municipal, divide o município em 1 sede, 6 distrito e 34 bairros.

O Balneário praia das Areias Brancas enfrenta algumas dificuldades, a vegetação que se localiza as margens dos rios, agem como um reservatório natural retendo os excessos de precipitação no período de estiagem, mantendo assim a vazão. Atualmente, com a redução desta área, reduziu-se a capacidade de regularização do fluxo. Durante os períodos de estiagem, ocorre o decréscimo da qualidade de água deste rio, devido à redução da capacidade de diluição dos despejos; e nas cheias, ele transborda inundando casas da zona ribeirinha e plantações.

O maior problema é o excesso de chuvas em algumas épocas do ano causando cheias e estado de emergência no município e escassez de água, na época de poucas chuvas.

Subindo ou descendo o Rio Santa Maria percebe-se um impacto de forma negativa em relação a seu fluxo, devido ao desmatamento em margens, aumentando a erosão e a carga de sedimentos no rio. A exploração inadequada de areia em margens, não permite a fixação de vegetação, mudando hábitos culturais da população rosariense, inclusive da população que vive a margem do rio e interferindo no estado de poluição das águas.

De acordo com os dados fornecidos pela FEPAM, observou-se que nos meses de Novembro e Dezembro de 2007, bem como meses de Janeiro e Fevereiro de 2008, não houve índice de Coliformes fecais que tornassem o Balneário da Praia das Areias Brancas impróprio para banho.

Os resultados desta pesquisa verificaram que as águas do Balneário Praia das Areias Brancas, classificam-se como excelentes, em relação a balneabilidade.

Comparando os dados das pesquisas, demonstra-se a conciliação entre a utilização do Balneário Praia das Areias Brancas como área de lazer e recreação com a qualidade da água para fins de balneabilidade, e constata-se que de acordo com cada época do ano a classificação se altera.Sendo que no verão a classificação das águas torna-se superior a do período de inverno, 
Monografias Ambientais

(e-ISSN: 2236-1308)

REMOANFSM

provando assim, que a presença dos veranistas não é a causadora dos altos índices de Coliformes termotolerantes.

Concluiu-se com este trabalho deve se conscientizar a população em preservar o Balneário, onde mudanças comportamentais devem ser buscadas, não só pela melhoria da infraestrutura sanitária, mas principalmente através do esclarecimento e informação da população do Município, promovendo também a Educação Ambiental.

\section{REFERÊNCIAS BIBLIOGRÁFICAS}

BALARINE, OFO (org). Projeto Rio Santa Maria, PUC-RS. Porto Alegre, 1999.

BARLOW, Maude; CLARKE, Tony. Ouro Azul. São Paulo: M. Books do Brasil, 2003.

BERNARDI, Ronaldo. A água e os rios. Publicação de acordo em ação civil pública proposta pelo ministério público do estado de São Paulo, 1998.

BOURSCHEID, Engenharia Ltda. Programa de recuperação e desenvolvimento da Bacia Hidrográfica do rio Santa Maria. Governo do Estado do Rio Grande do Sul- Secretaria das obras públicas, saneamento Habitação. Porto Alegre, 1997.

BRAGA, Benedito. Introdução à Engenharia Ambiental. São Paulo: Prentice Hall, 2002.

CORSON, Walter H. Manual Global de Ecologia: o que você precisa fazer a respeito da crise do meio ambiente. São Paulo: AUGUSTUS, 1996.

CRH-RS. Conselho de Recursos Hídricos do Rio Grande do Sul e comitê de Gerenciamento da Bacia do Rio Santa Maria. Porto Alegre, 2000. 
FEPAM, Fundação Estadual de Proteção Ambiental Henrique Luiz Roessler. Disponível em: http://www.fepam.rs.gov.br/qualidade/balnearios_rhuruguai.asp Acesso em: 05 de Setembro de 2008.

LEAL, Alzira Elaine Melo; SOUZA, Carlos Eduardo Gerson de Souza. Construindo o conhecimento pela pesquisa: Orientação básica pra elaboração de trabalhos científicos. Santa Maria: Sociedade Vicente Pallotti, 2006.

MOTA, Suetônio. Introdução à Engenharia Ambiental. Rio de Janeiro: Associação Brasileira de Engenharia Sanitária e Ambiental, 2000.

OLIVEIRA, L. Mergulho na água. Superinteressante, (n³7). São Paulo: Abril, 1990.

PHILIPPI JR., Arlindo. Saneamento, Saúde e Ambiente: fundamentos para um desenvolvimento sustentável. Barueri, São Paulo: Manole, 2005.

PHILIPPI JR., Arlindo; ROMÉRO, Marcelo de Andrede; BRUNA, Gilda Collet. Curso de Gestão Ambiental. Barueri, São Paulo: Manole, 2004.

PINTO-COELHO, Ricardo Motta. Fundamentos em Ecologia. Porto Alegre: Artmed, 2000.

REFATTI, Thales. Licenciamento Ambiental: Avaliação do Balneário São Simão, Município de Cacequi, RS, Brasil. Estudo de Caso. 2006.

SOUZA, Nara Miranda. Subsídio de Orientação, assim é Rosário do Sul. Gráfica Sara, 1996.

RICKLEFS, Robert E. A Economia da Natureza. 5.ed. Rio de Janeiro: Guanabara Koogan, 2003. 
Monografias Ambientais (e-ISSN: 2236-1308)

REMOANFSM

SPERLING, Marcos Von. Introdução à Qualidade das Águas e no Tratamento de Esgotos. Belo Horizonte: Editora UFMG, 2000.

TORTORA, Gerard J.; FUNKE, Berdell R.; CASE, Christine L. Microbiologia. 6.ed. Porto Alegre: Artmed, 2000.

MADIGAN, Michael T.; MARTINKO, John M.; PARKER, Jack. Microbiologia de Brock. São Paulo: Prentice Hall, 2004. 